\title{
Evaluation of combines transport support effectiveness for harvesting silage crops in Western Siberia
}

\author{
Rufan Galimov ${ }^{1,2^{*}}$, Kirill Maksimovich ${ }^{1,2}$, and Vitaliy Tikhonovskiy ${ }^{1}$ \\ ${ }^{1}$ Novosibirsk SAU, 160, Dobrolyubova str., 630039, Novosibirsk, Russia \\ ${ }^{2}$ Siberian Federal Scientific Centre of Agro-BioTechnologies of the Russian Academy of Sciences \\ P.O., box 267, 630501, Krasnoobsk, Novosibirsk region, Russia
}

\begin{abstract}
In this work we calculated the forage harvester required power to provide the smooth operation of transport which are responsible for the green mass transportation. Effectiveness assessment of the enterprise, harvesting forage crops through the positioning and monitoring of transport. Methods are proposed to optimize the harvesting process in order to reduce downtime of forage harvesters and increase economic efficiency.
\end{abstract}

\section{Introduction}

Large volumes of transportations in agriculture are carried out during harvesting, including harvesting feed crops. When organizing the harvesting and transport process, strict coordination of transport with forage harvesters is required, otherwise, due to an accidental change in the operating cycles of forage harvesters and vehicles, the productivity of the harvesting and transport complex decreases. With the harvesting of green mass in the optimal agronomic terms with minimal costs, you can solve it using high-performance equipment that will correspond to the land resource of an agricultural enterprise $[1,2,3]$. Today, the technical resource based on old technology had outdated and has no way to develop. The labor resource in the countryside is reduced and the agricultural enterprise is forced to purchase expensive, high-performance equipment in large quantities. In this case, it is advisable to prefer technical means to ensure the feed procurement process and organize their effective use in conditions where there is not enough modern methodological and recommendation base, and agricultural equipment manufacturers and their dealers are limited only by advertising data and a brief technical description of the machines is a significant problem $[5,6,1,2]$. The analysis of the Novosibirsk region machinery fleet according to the Ministry of Agriculture on April 1, 2017 totals: 646 units, of which only $80 \%$ are technically ready for work. It follows from the data presented from Rosstat, that a large number of forage harvesters in the NSO are Don-680 (148 units). The trucks fleet in the Novosibirsk Region totals 5073 units, and the tractor fleet - 10191 units, of which 517 tractor units are from agricultural producers, among them $88 \%$ are operational (for 2017).

\footnotetext{
* Corresponding author: kiri-maksimovi@mail.ru
} 
Reducing the technical equipment and underutilization of equipment capabilities significantly increases the actual duration of harvesting works in comparison with the calculated data, and entails large, up to a quarter, crop losses. This problem was resolved on the basis of harmonious functioning parameters of complex processes, the establishment of mutual influence of the ripening dynamics of early maturity varieties, crops and technical equipment of harvesting processes, the introduction of reserve and compensating elements. The paper presents a methodology to justify the appropriate number of machines and the number in the link for harvesting corn for silage. Using the harvesting process modeling, it was found that combining variety 3 groups with an area ratio allows increasing rational seasonal productivity per combine from 400 to 600 hectares $[5,6]$. Significant crop losses on silage arise from non-compliance with the agrotechnical harvesting dates. Lengthening the harvesting time due to the lack of forage harvesters or vehicles, leads to the fact that in addition to significant losses during harvesting, the harvested crops are not ripened before the autumn weather, and in the northern zones even before the snow falls [6]. Large volumes and short agrotechnical deadlines for fodder harvesting in agricultural enterprises require the involvement of a significant number of equipment and labor resources. The main reserve for increasing fodder production is to reduce crop losses while reducing the time required to complete work by increasing the performance of hopper-free harvesting machines by creating effective technological systems for using transport [7,8]. When harvesting silage, the most important link is the transportation of green mass from forage harvesters to places of silo. Currently, many agricultural enterprises use high-performance forage harvesters for silage harvesting, the throughput of which reaches $200 \mathrm{t} / \mathrm{h}$. When analyzing forage harvesters and transport fleet state, the requirements of new approaches to solving transport problems that contribute to a radical improvement of the transport process when harvesting silage crops were revealed. It is difficult to use the potential of forage harvester with limited number and obsolete, worn-out transport, and downtime of the forage harvesters bring significant material costs [6]. The relevance of our study is also due to the fact that in most agricultural enterprises of Novosibirsk region there is a problem of updating the transport fleet and forage harvesters involved in harvesting green mass. The work of different scientists at different times devoted to the interaction of forage harvesters and vehicles, the development of harvesting, transport and other processes in agricultural production: Y.N. Blynsky, V.D. Ignatov, Y.A. Guskov, A.Y. Izmailov, V.V. Tikhonovsky, etc.

The aim of the study is to evaluate the performance of forage harvesters and satellite vehicles in the Novosibirsk region, designed for harvesting corn for silage, as well as the performance of forage harvesters through monitoring and positioning.

A number of the following tasks were set: to conduct practical research on transport services during direct-flow transportation of forage harvesters, taking into account working conditions; compare theoretical and actual data on the performance of the forage harvester and suggest methods for optimizing the harvesting and transport system for harvesting corn for silage.

\section{Materials and methods}

The main objective of the two-year study is to evaluate the effectiveness of the use of forage harvesters in the territory of the Verkh-Irmen enterprise, Novosibirsk Region, in 2018 and 2019. All work was carried out in the autumn period of agronomic works, during the harvesting of corn for silage. The data was obtained through test on the actual units by installing GPS equipment on a forage harvester. The obtained data processing was carried out using statistical analysis. The harvesting and transport process investigation was carried out using modeling methods on PC in MapSource 6.16.3 and KOMPAS-3D 16v. 
Feasibility study of the harvesting and transport process for various patterns of interaction of harvesting and transport vehicles has been carried out. The following software was also used: Microsoft Word, Excel.

Calculation of theoretical performance of forage harvesters:

$$
W_{f h}=0,1 B_{w} V_{w} \tau H,
$$

where $\mathrm{W}_{\mathrm{fh}}$ - forage harvester productivity, $\mathrm{t} / \mathrm{h} ; \tau$ - coefficient of shift time using; $\mathrm{H}$ - crop yield, $\mathrm{t} / \mathrm{ha}$. $\mathrm{V}_{\mathrm{w}}$ - harvester working speed, $\mathrm{km} / \mathrm{h}$

$$
B_{\mathrm{p}}=B_{h} \beta,
$$

where $\mathrm{Bw}$ - working width of header, $\mathrm{Bh}$ - header width, $\mathrm{m} ; \beta=0,95$.

Dependence of harvested area size on the housing volume when transporting grasses green mass $\left(\mathrm{F}_{\text {sil }}\right)$ calculated by an empirical indicator composition (sil)

$$
F_{\text {sil }}=c_{\text {sil }} V_{H},
$$

Calculation of the dependence of harvested area size on the housing volume when transporting corn green mass $\left(\mathrm{F}_{\text {sil.h }}\right)$ calculated by an empirical indicator composition $\left(\mathrm{c}_{\text {sil.h }}=\right.$ $0,02)$ and $\left(\mathrm{V}_{\mathrm{h}}\right)$ vehicle housing volume:

$$
F_{\text {sil.h }}=c_{\text {sil.h }} V_{H}
$$

Silo transport performance depending on trailer housing volume, by multiplying combine harvester productivity $\left(\mathrm{W}_{\mathrm{sil}}\right)$ and an empirical indicator $\left(\mathrm{B}_{\mathrm{sil}}=0,43\right)$ :

$$
W_{\text {sil }}=\mathrm{B}_{\text {sil }} V_{H},
$$

The dependence of the required power varies on the housing volume in proportion:

$$
N_{\text {sil }}=a_{\text {sil }} V_{H},
$$

Change in trailer mass from housing volume:

$$
P=k_{n} V_{H},
$$

where $\mathrm{P}$ - trailer weight, $\mathrm{kg} ; \mathrm{V}_{\mathrm{H}}$ - housing trailer volume, $\mathrm{m}^{3} ; \mathrm{n}_{\mathrm{k}}-$ an empirical coefficient having a dimension of $\mathrm{kg} / \mathrm{m}^{3}$ and equal 125 .

\section{Research results and discussion}

CJSC Verkh-Irmen is located in Ordynsky district of Novosibirsk Region. The main economic activity is the production and processing of grain, meat, milk. At this agricultural enterprise, Jaguar 850 forage harvesters with header width of 4.5 and KamAZ $45143+$ 2PTS-7 vehicles were used, average loading time of which is 10.59 minutes, with distance to the silo of $3 \mathrm{~km}$. Fig. 3, 4 shows the movement pattern of the forage harvester with downtime marks and unproductive runs on the field.

The study results for 2018 and 2019 on the agricultural enterprise Verkh-Irmen showed that there are large differences between forage harvesters theoretical and actual productivity. In 2019, with header working width of $4.275 \mathrm{~m}$, the estimated capacity of Jaguar 850 forage harvester for the example of harvesting silo with yield of 25 tons per ha is $136.27 \mathrm{t} / \mathrm{h}$. Actual productivity is $84 \mathrm{t} / \mathrm{h}$ (Table 1). This indicator is quite low, due to the fact that forage harvester downtime occurs due to transport services improper organization. 
Data on actual productivity for 2018 with the same theoretical productivity of $136.27 \mathrm{t} / \mathrm{h}$ and the same yield of 25 tons per ha (distance from the field to the silo of $4.2 \mathrm{~km}$ ), amounted to $60 \mathrm{t} / \mathrm{h}$ (Fig. 3).

Table 1. Theoretical and actual forage harvester productivity for 2018/19.

\begin{tabular}{|l|c|c|}
\hline \multicolumn{1}{|c|}{ Year } & $\mathbf{2 0 1 8}$ & $\mathbf{2 0 1 9}$ \\
\hline Theoretical productivity, $\mathrm{t} / \mathrm{h}$ & 136.27 & 136.27 \\
\hline Actual productivity, $\mathrm{t} / \mathrm{h}$ & 60 & 84 \\
\hline
\end{tabular}

This farm did not use harvesting and transport process logistically controlled model. All this led to downtime of forage harvesters due to inconsistency of transport support on the field. It was also established with the help of experimental observations that no communication means were used between forage harvesters and vehicles. This greatly affects the vehicle motion coordination in the field (Fig. 3, Fig. 4).

To reduce transport costs when using vehicles for harvesting, it is necessary to reduce the downtime of forage harvesters to wait for vehicles by reducing unproductive vehicle mileage through the use of positioning, monitoring and improving technical means.

This is due to the fact that in present conditions, the time of filling the vehicle trailer with silage and the time of another vehicle arrival on the field do not match.

The vehicles interaction in harvesting silo process must be formed so that the forage harvesters work with less time losses awaiting vehicles. But taking into account the distance from the field to the siloing places, the vehicle turnaround time is not constant and varies over large boundaries, it would involve connecting a significant number of vehicles that were idle for a significant part of the shift working time, which is not economically rational.

Figure 1 shows the graphical dependence of change in the vehicle housing volume on the trailer mass when transporting corn silage. It is noticeable that change in the trailer mass from the vehicle housing volume has the proportional dependence.

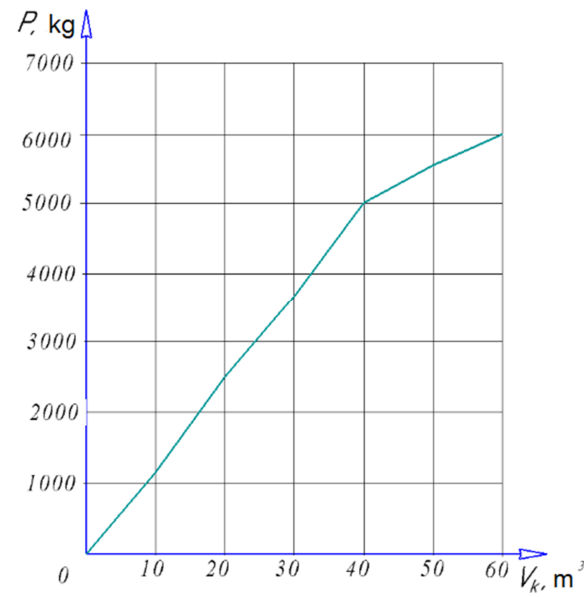

Fig. 1. Dependence of housing volume of green mass power. Where: 1 - when transporting hay mass from herbs; 2 - when transporting silage from corn.

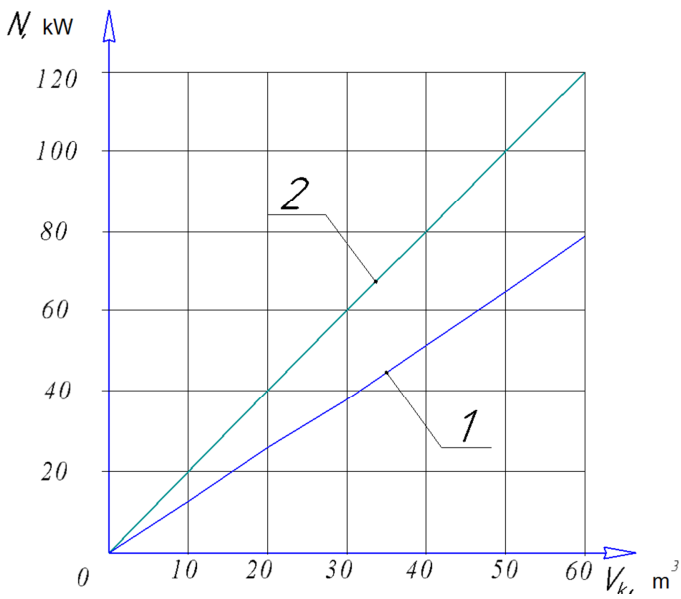

Fig. 2. Dependence of required combine.

In the calculations, such weather conditions are accepted when, after three days of good weather, precipitation falls on the fourth day; productivity per hour of working time is determined by multiplying productivity per hour of working time by a factor of 0.7 , which takes into account the use of the trailer housing volume of the transported green mass, the 
technical readiness of the vehicle, idle runs, repairs and stops to wait for transport. Then, taking into account organizational measures during an eight-hour shift, trailers operate on transportations daily for 5-6 hours. The corn silage yield is $250 \mathrm{c} / \mathrm{ha}$, losses during harvesting about $10 \%$.

These calculations and the dependence of changes in technical and technological parameters will help in the new special agricultural vehicles design, as well as determining the required number of vehicles for servicing forage harvesters and transporting green mass from combines to the place of silage.

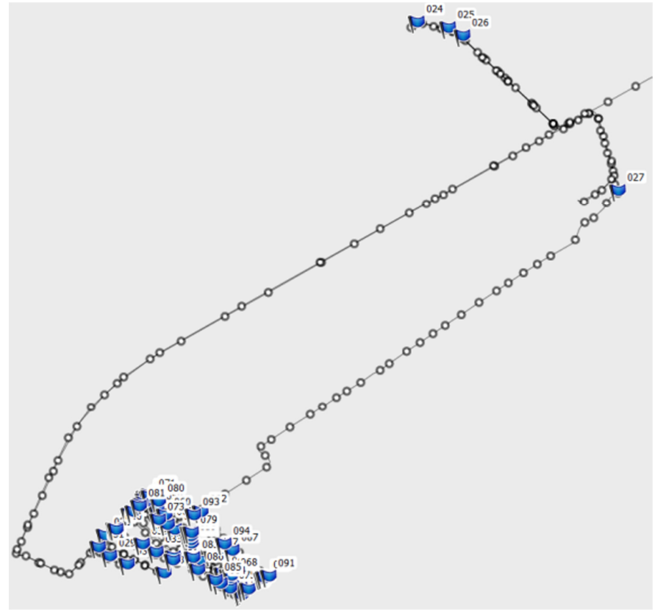

Fig. 3. Forage harvester trajectory map for 2018.

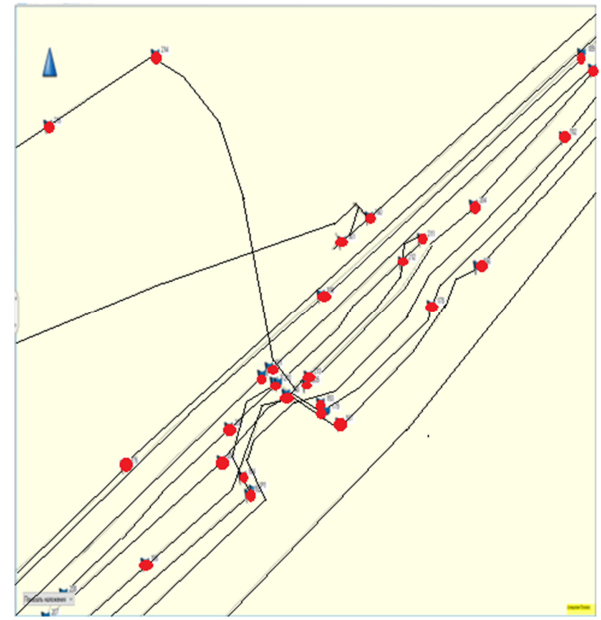

Fig. 4. Forage harvester trajectory map for 2019.

In addition of the different trailers and accessories brands, it is advisable to classify by housing volume at intervals of $10 \mathrm{~m}^{3}$. Vehicles with housing volume from 10 to $20 \mathrm{~m}^{3}$ is advisable to attribute to the first class. Vehicles with housing volume from 21 to $31 \mathrm{~m}^{3}$ is advisable to attribute to the second class. To the third class $-32 \ldots 42 \mathrm{~m}^{3}$, to the fourth class $-43 \ldots .53 \mathrm{~m}^{3}$ and to the fifth $-54 \ldots 64 \mathrm{~m}^{3}$ (table 2).

Table 2. Dependence of the harvested area on the housing volume and class of vehicles.

\begin{tabular}{|l|c|c|c|c|c|}
\hline \multicolumn{1}{|c|}{ Names } & \multicolumn{5}{|c|}{ Indicators } \\
\hline Housing volume, $\mathrm{m}^{3}$ & $10 \ldots 20$ & $21 \ldots 31$ & $32 \ldots 42$ & $43 \ldots 53$ & $54 \ldots 64$ \\
\hline $\begin{array}{l}\text { Trailer } \\
\text { classification, class }\end{array}$ & 1 & 2 & 3 & 4 & 5 \\
\hline $\begin{array}{l}\text { Harvesting area } \\
\text { when harvesting } \\
\text { green mass, ha }\end{array}$ & $0,20 \ldots 0,40$ & $0,42 \ldots 0,62$ & $0,64 \ldots 0,84$ & $0,86 \ldots 1,0$ & $1,08 \ldots 1,28$ \\
& & & & & \\
\hline $\begin{array}{l}\text { Continuous working } \\
\text { time, min }\end{array}$ & 4,30 & 10 & 15,16 & 20 & 26 \\
& & & & & \\
\hline Names & 2PTS-7 & ПPC-30 & Fliegl-ASW & Tonar & Tonar \\
& 2PT-6 & & 381 & 95234 & 952342 \\
& 2PT-9 & & & & \\
& Kamaz & & & & \\
& 45143 & & & & \\
\hline 55102 & & & & \\
\end{tabular}




\begin{tabular}{|l|c|c|c|c|c|}
\hline Forage harvesters & KSK-100 & Don 680m & JAGUAR & New & BiG X 700 \\
& KSK-600 & KVK 800 & 860 & Holland & BiG X 770 \\
& RSM 100 & & John Deere & FR & JAGUAR \\
& & & 8100 & & 960 \\
\hline
\end{tabular}

The first group is equipped with trailers and cars: 2PTS-7, 2 PTS -6, 2 PTS -4, 2 PTS 9, Kamaz 45143 /55102 and forage harvesters: KSK-100, KSK-600, RSM 100.

The second group is equipped with trailers and cars: special PS-30 semi-trailer and forage harvesters: Don $680 \mathrm{~m}$, KVK 800.

The third group is equipped with trailers and cars: Fliegl-ASW 381 and forage harvesters: JAGUAR 860, John Deere 8100, New Holland FR.

The fourth group is equipped with trailers and cars: Tonar 95234 and forage harvesters: New Holland FR.

The fifth group is equipped with trailers and cars: Tonar-952342 and forage harvesters: BiG X 700, BiG X 770, JAGUAR 960 (tab. 1.2).

As a result of two years of research, it was found that the actual performance of the forage harvester for harvesting corn for silage is significantly lower than the theoretical productivity. This is due to downtime of the forage harvester on the field due to transport services improper organization. In connection with a large decrease in the number of tractors, it is necessary to develop new methods that take into account the age of the equipment and its inadequacy to field work. New developments are needed using modern positioning and monitoring tools, taking into account the current state of vehicles.

\section{Conclusion}

As a result of two years of research, it was found that the actual performance of the forage harvester for harvesting corn for silage is significantly lower than the theoretical productivity. Actual data on the performance of forage harvesters have been obtained: $2018-60 \mathrm{t} / \mathrm{h} ; 2019-84 \mathrm{t} / \mathrm{h}$ on field, when harvesting corn for silage with yield of 25 tons per hour with working header width of $4,275 \mathrm{~m}$.

It is established that the main problems associated with forage harvester low productivity are: lack of transport support, inconsistency of transport support on the field, lack of communication equipment between combines, vehicles and team leader.

The solution to this problem may be introduction of positioning and monitoring of technical equipment on the field, taking into account random distribution of places where the housing is filled up. Optimization is possible by reducing or increasing the technically established capacity of the forage harvester depending on the number and vehicle housing volume. The calculations and patterns of changes in technical and technological parameters can be used in new special agricultural vehicles design, as well as to determine the required number of vehicles, for transportation of shredded green mass from forage harvester to places of silo. All this will help to increase the harvesting process manage efficiency and avoid the forage harvesters and vehicles downtime.

\section{References}

1. Z.I. Usanov et al., Economy, Work, Management in Agriculture 1, 79-83 (2018)

2. S. Mashkov et al., IOP Conference Series: Earth and Environmental Science 403(1), 012079 (2019)

3. T.P. Kharel et al., Agronomy Journal 111(2), 509-516 (2019) 
4. E. Cavallo, E. Ferrari, M. Coccia, Int. J. Technology, Policy and Management 15(2), 158-177 (2015)

5. V.V. Prokhorova et al., International review of management and marketing 6(6S), 159164 (2016)

6. S. Candiago et al., Remote sensing 7(4), 4026-4047 (2015)

7. Y.I. Bershickiy et al., Polythematic Online Scientific Journal of Kuban State Agrarian University, 1715-1729 (2015)

8. L. Pari et al., Biomass and Bioenergy 107, 398-410 (2017)

9. W.J. Sacks et al., Global Ecology and Biogeography 19(5), 607-620 (2010)

10. J. Moudrý jr, J. Moudrý, Organic Agriculture Towards Sustainability, 247 (2014)

11. A.A. Polukhin, Bulletin of Agricultural Science 50(5), 12-18 (2014)

12. V. Zubina, A. Kutyrev, MATEC Web of Conferences. EDP Sciences 298, 4 (2019)

13. J. Mahirah, K. Yamamoto, M. Miyamoto, N. Kondo, Y. Ogawa, T. Suzuki, H. Habaragamuwa, U. Ahmad, Engineering in Agriculture, Environment and Food 10(2), 140-149 (2017)

14. C. Amiama, J. M. Pereira, A. Castro, J. Bueno, Computers and Electronics in Agriculture 118, 56-65 (2015)

15. P. Busato, A. Sopegno, N. Pampuro, L. Sartori, R. Berruto, Biosystems Engineering 180, 146-160 (2019) 